\title{
Pemeliharaan Mesin Mobil Listrik Sula Politeknik Negeri Subang
}

\author{
Adhan Efendi*, Azhis Sholeh Buchori \\ Jurusan Pemeliharaan Mesin, Politeknik Negeri Subang \\ Jl. Brigjen Katamso No. 37, Dangdeur, Kabupaten Subang, Jawa barat 41211 \\ *E-mail: adhan@polsub.ac.id \\ Diterima: 09-11-2019; Direvisi: 04-12-2019; Dipublikasi: 31-12-2019
}

\begin{abstract}
Abstrak
Penelitian ini bertujuan untuk membuat rencana pemeliharaan mesin mobil listrik sula dengan metode inspeksi, small repair, medium repair, overhaul (ISMO). Waktu pemeliharaan dengan jenis perawatan mesin secara bulanan. Metode pelaksanaan pemeliharaan mesin mobil sula meliputi studi literatus, pembuatan jadwal, dan validasi ahli. Komponen yang dilakukan pemeliharaan pada system mekanik yang meliputi casis, system pengereman dan system kelistrikan. Hasil penelitian menunjukan bahwa pemeliharaan mesin mobil sula dimaksudkan untuk menjaga kondisi mesin mobil tetap pada performa terbaik.
\end{abstract}

Kata kunci: ISMO, Mobil Listrik Sula, Pemeliharaan

\begin{abstract}
This study aims to make a plan for maintaining Sula's electric car engine with inspection methods, small repair, medium repair, overhaul (ISMO). Maintenance time with this type of machine maintenance is on a monthly basis. The method of implementing Sula's car engine maintenance includes the study of literature, making a schedule, and validation by experts. Components that are carried out maintenance on the mechanical system which includes the chassis, braking systems and electrical systems. The results showed that the maintenance of Sula's car engine was intended to maintain the condition of the car's engine at its best performance.
\end{abstract}

Keywords: ISMO, Sula Car Electric, maintenance

\section{Pendahuluan}

Berkembangnya teknologi dibidang otomotif terciptanya yang namanya mobil listrik, mobil listrik salah satu kendaraan tanpa emisi seperti halnya kendaraan berbahan bakar minyak ini merupakan salah satu alternative untuk mengurangi polusi udara. Ditambahkan oleh Nyaga [1] penggunaan mobil berbahan bakar cair dapat menghabiskan sumber daya alam dan menimbulkan kerusakan ozon. Pencegahan paling efektif yaitu mencari pilihan utama untuk transportasi alternatif: hibrida kendaraan, kendaraan sel bahan bakar hidrogen, bahan bakar bio, dan kendaraan listrik.

Mobil listrik merupakan mobil masa depan, mobil listrik menjadi pilihan karena efisiensi dan rendahnya polusi yang dihasilkan Guizani dkk. [2]. Ditambahkan oleh Quandt dkk. [3] beberapa kelebihan mobil listrik dengan mobil berbahan bakar cair adalah suara yang halus, tidak berbau, dan bebas dari asap.

Di Indonesia, mobil listrik berkembang pesat dikalangan perguruan tinggi. Banyak perguruan tinggi yang sudah memiliki kendaraan listrik seperti mobil Politeknik Bandung, mobil listrik simadu Universitas Subang, mobil listrik batman ITS, dan mobil listrik Politeknik Negeri Subang. Untuk menjaga kondisi mobil listrik agar mobil listrik dapat digunakan sebagai media pembelajaan, dilakukanya perawatan secara berkala pada mobil listrik tersebut sesuai jadwal perawatan yang telah ditentukan. Mobil listrik sula masih sudah melalui tahap desain, manufaktur, dan uji coba kendaraan, sehingga dibutuhkan proses pemeliharaan untuk menjaga kondisi kendaraan.

Menurut Corder [4] pemeliharaan mesin terbagi dua yaitu pemeliharaan terencana dan pemeliharaan tak terencana, dalam bentuk pemeliharaan darurat (breakdown maintenance), pemeliharaan terencana (planned maintenance) merupakan kegiatan pemeliharaan yang dilaksanakan berdasarkan perencanaan terlebih dahulu. Pemeliharaan terencana ini terdiri dari pemeliharaan pencegahan (preventive maintenance) dan pemeliharaan korektif (corrective maintenance). Pemilihan jenis pemeliharaan preventif atau korektif akan mempengaruhi tenaga dan biaya yang dikeluarkan, sehingga pemilihan jenis pemeliharaan dilakukan secara tepat dan efektif [5]. 
Pemeliharaan pencegahan adalah jenis pemeliharaan yang dipilih oleh peneliti dikarenakan faktor kesesuaian dengan kondisi mobil mesin saat ini. metode yang digunakan inspeksi, small repair, medium repair, overhaul (ISMO). Rusuma [6] dalam master tesisnya dijelaskan bahwa pelayanan pemeliharaan mesin dibutuhkan untuk menjaga kondisi kendaraan, poin utamanya juga terletak pada teknisi yang berkompetensi. Ditambahkan oleh Efendi dkk. [7] pelaksaan kegiatan pemeliharaan mesin harus memperhatikan aspek keselamatan dan kesehatan kerja, mulai dari sisi standar kerja, alat, dan sarana pendukung. Efendi [8] kecelakaan kerja dapat dihindari apabila teknisi yang melakukan kerja praktik mematuhi aturan yang sudah ditetapkan.

Berdasarkan urgensitas permasalahan diatas, maka untuk menjaga kondisi mobil listrik yang prima tentunya dibutuhkan pemeliharaan terhadap mobil listrik yang maksimal dan menyeluruh sesuai jadwal pemeliharaan yang telah ditentukan seperti melakukan pengecekan, penyetelan, pembersihan, serta penggantian pada komponennya.

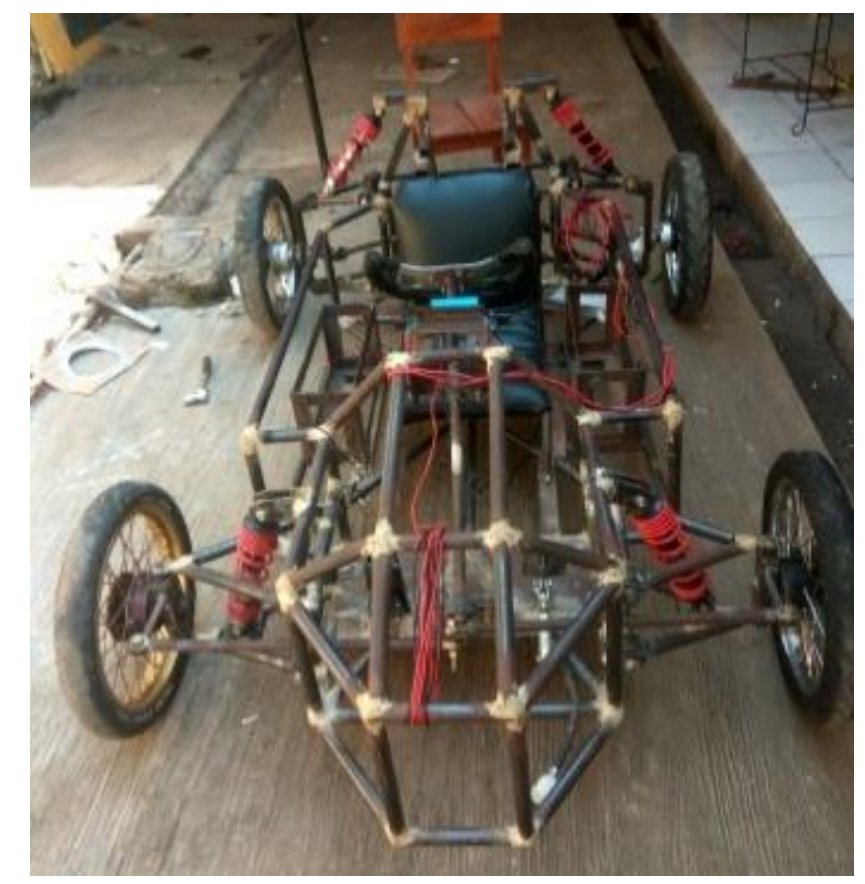

Gambar 1. Mobil Listrik Sula

\section{Material dan metodologi}

Penelitian mobil listrik SULA'16 1.0 dilaksanakan pada tanggal 2 Januari 2019 s/d 15 Juli, penelitian bertempatan dibengkel kampus Politeknik Negeri Subang. Peneliti melakukan studi literature untuk mengumpulkan informasi terkait pemeliharaan komponen mesin, setelah itu pembuatan jadwal bulanan mesin, jadwal yang telah dibuat berupa log sheet preventive maintanance prototipe mobil listrik, lalu log sheet tersebut diserahkan kepada para ahli untuk diketahui dan dilakukan pengujian oleh para ahli. Kemudian dilakukan pelaksaan pemelihaaran mesin dengan jadwal perawatan yang telah divalidasi. Data yang dikumpulkan melalui dokumentasi, observasi, dan pelaksaaan kemudian dianalisis secara desktiptif kualitatif, adapun tahapan penelitian dapat dilihat pada Gambar 2. 


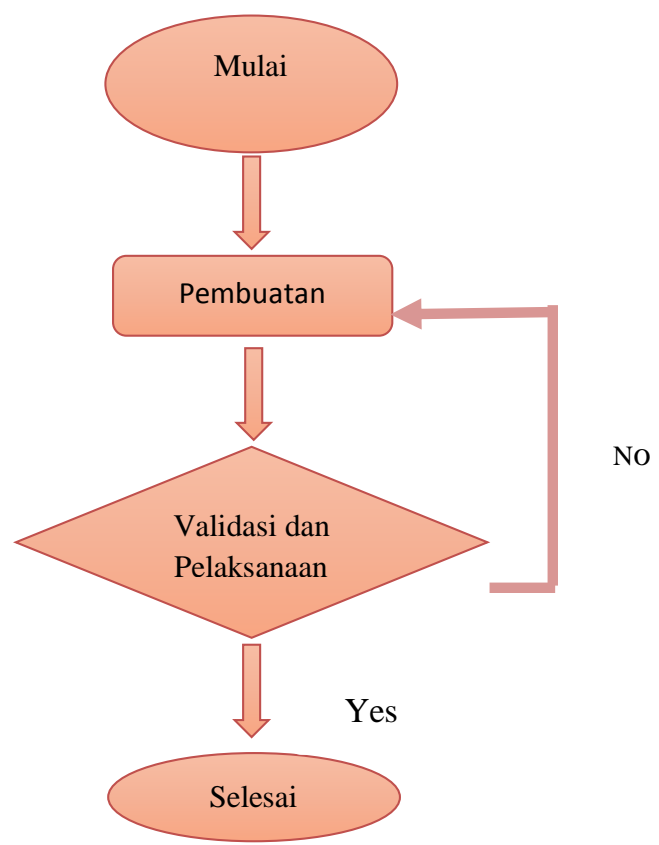

Gambar 2. Tahapan Penelitian

\section{Hasil dan pembahasan}

\subsection{Jadwal Pemeliharaan}

Proses pembuatan jadwal pemeliharaan mobil listrik sula ditentukan dari hasil pengamatan pada spesifikasi setiap komponennya serta mengumpulkan data-data dari manual book yang didapat, berikut jadwal pemeliharaan.

Tabel 1. Jadwal Pemeliharaan

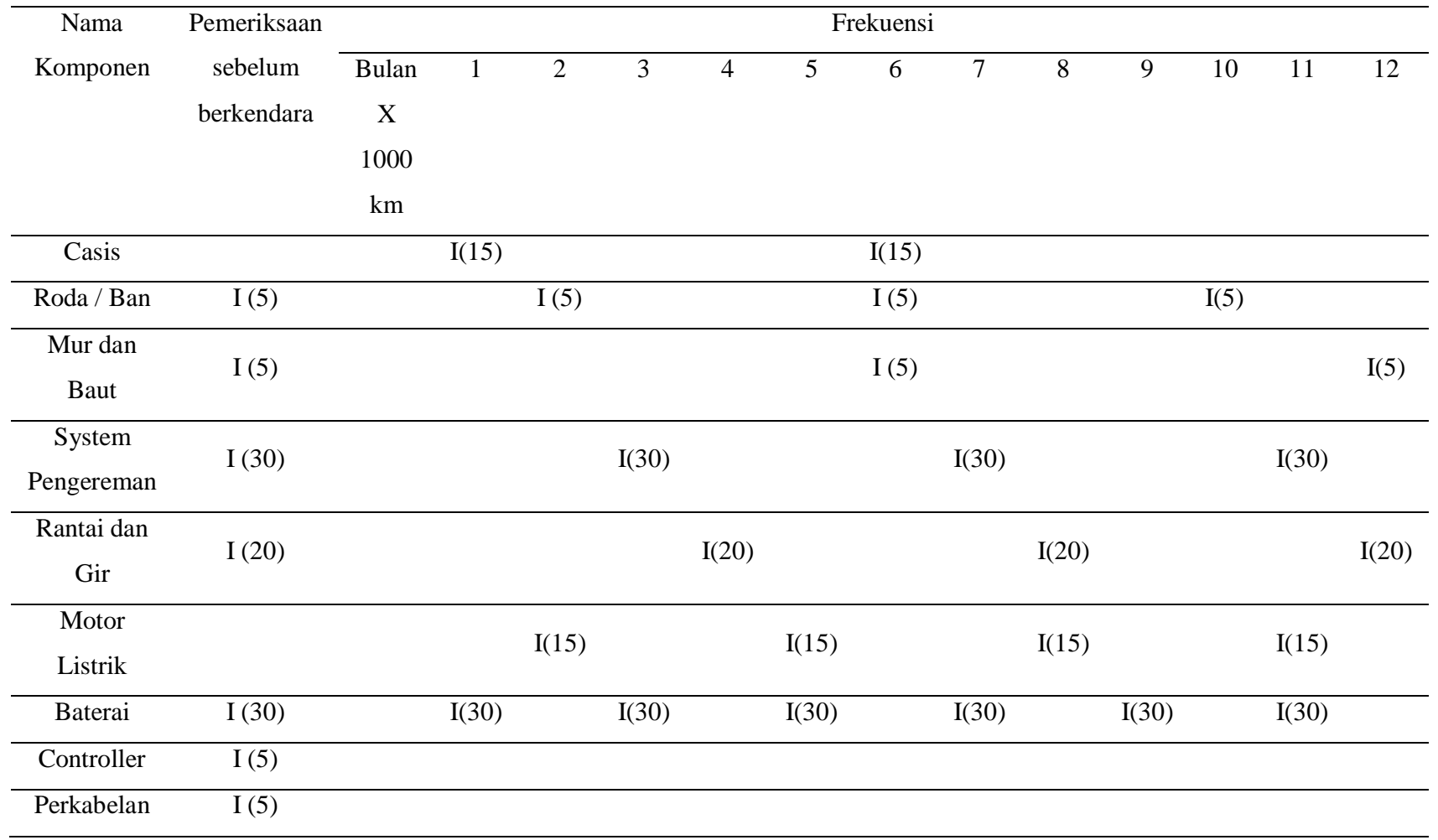


Pemeliharaan yang diterapkan dalam mobil listrik sula yaitu pemeliharaan bulanan yang dimana dilakukanya setiap satu bulan sekali atau tiga bulan sekalai bahkan setiap enam bulan sekali. pemeliharaan prototipe mobil listrik yaitu inspeksi, tetapi tidak menutup kemungkinan kegiatan pemeliharaan tersebut bisa sampai overhaul dengan catatan apabila kondisi komponen tersebut harus dilakukan kegiatan tersebut.

\subsection{Pelaksanaan Pemeliharaan}

Komponen yang dilakukan pemeliharaan pada system mekanik prototype mobil listrik SULA meliputi casis, system pengereman, dan baterai.

\section{Casis}

Komponen pada casis yang harus dilakukan pemeliharaan yaitu pada bantalan yang terdapat pada casis seperti arm dan kemudi, pemeliharaan yang dilakukan pada bantalan agar bantalan dapat beroperasi dengan baik berupa pemeliharaan (bersihkan, lumasi dan ganti bila perlu) yang dilakukan sesuai jadwal pemeliharaan yang sudah direncanakan.
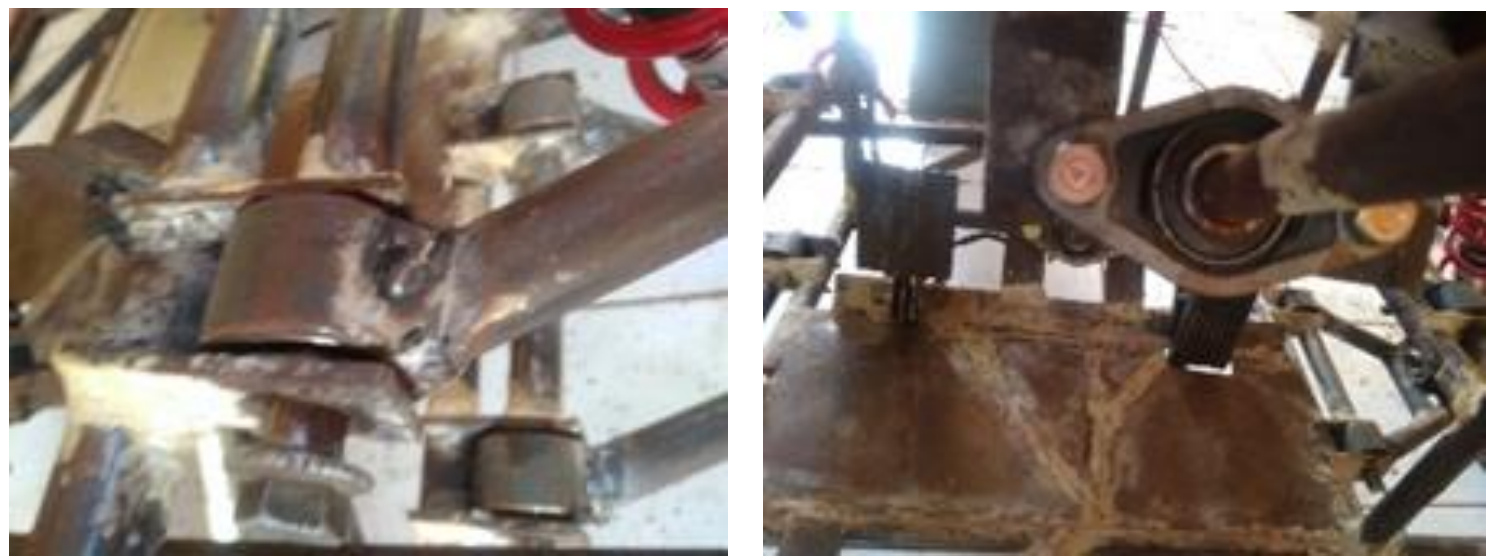

Gambar 4. Bantalan Pada Arm dan Kemudi

Ditambahkan oleh Amin [9] bahwa casis merupakan komponen penting di mobil listrik. Proses pembuatan casis harus memperhatikan desain, sains, dan factor pendukung lainnya. Setelah mobil selesai dibuat, dibutuhkan pengecekan kondisi casis, casis umumnya mengalami korosi yang harus segera dilakukan perawatan pada bagian tersebut.

\section{Sistem Pengereman}

Pemeliharaan yang diilakukan pada system pengereman prototype mobil listrik sula agar system pengereman dapat beroprasi dengan baik maka perlu dilakukan pemeliharaaan pada setiap komponennya, berikut komponen yang perlu dilakukan pemeliharaan

1. Pemeriksaan minyak rem apakah minyak rem sudah habis atau belum apa bila minyak rem habis, maka minyak rem bias ditambah kembali. 


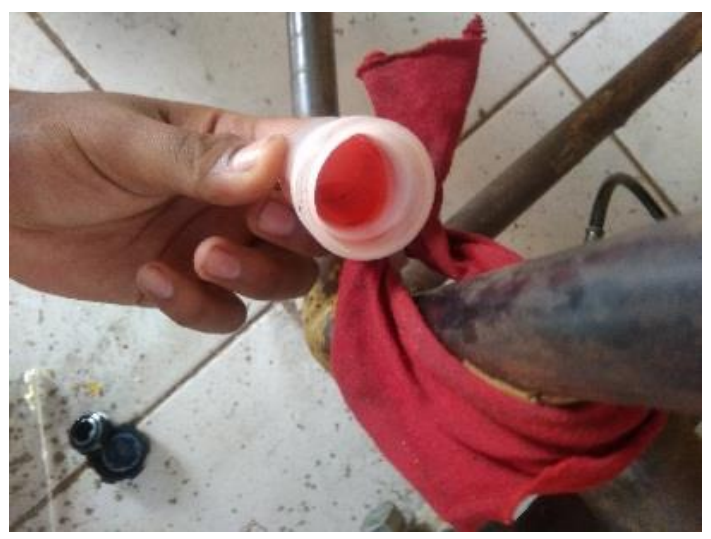

Gambar 5. Pengecekan Minyak Rem

2. Pemeriksaan kanvas rem, pemeriksaan yang dilakukan berupa bersihkan dan memeriksa keausan kanvas remnya.

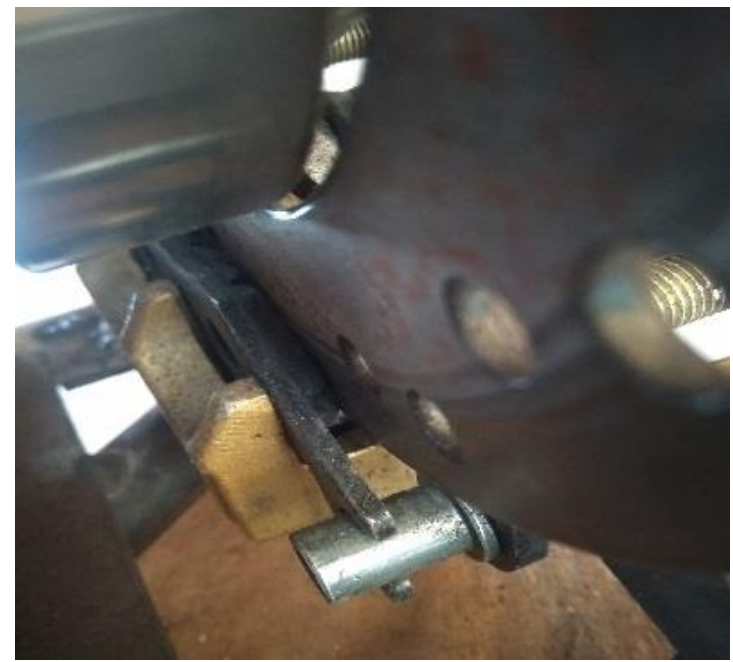

Gambar 6. Pemeriksaan Kanvas Rem

3. Pemeriksaan piringan cakram, pemeriksaan yang dilakukan berupa bersihkan serta keausan piringan cakram rem. Pemeliharaan dilakukan sesuai jadwal pemeliharaan yang telah direncanakan dan dilaksanakan tepat waktu sesuai jadwal.

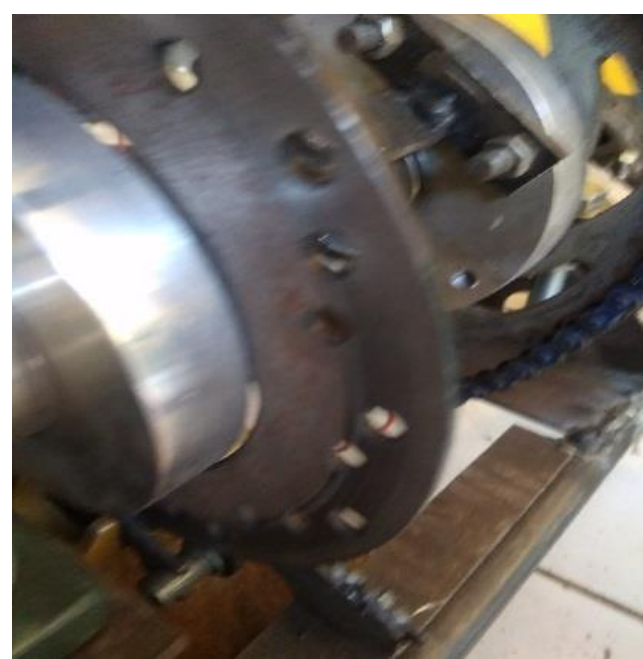

Gambar 7. Pemeriksaan Cakram Rem 
Diperjelas oleh Maccioni [10] sistem power train dan brake merupakan komponen utama sebagai penggerak kendaraan dan pengaman kendaraan agar selaluaman. Dibutuhkan perawatan yang memenuhi standar untuk kedua komponen utama tersebut.

\section{Baterai}

Baterai merupakan sumber tegangan dan sebagai penyimpan tegangan yang terdapat pada prototipe mobil listrik sula agar baterai beropasi dengan baik maka perlu dilakukan pemeliharaan, berikut pemeliharaan pada baterai:

1. Pemeriksaan voltase yang dihasilkan baterai, apabila voltase $<12$ volt maka perlu dilakukan pengecasan pada baterai, dapat dilihat pada gambar 8

2. Pengecekan air accu (elektrolit) yang terdapat pada baterai.

apabila air accu dibawah level min maka harus dilakukan pergantian air accu, apabila air accu di atas level max maka harus dilakukan pengurangan pada air accu, air accu dinyatakan standar tepat ditengah-tengah level min dan level max.

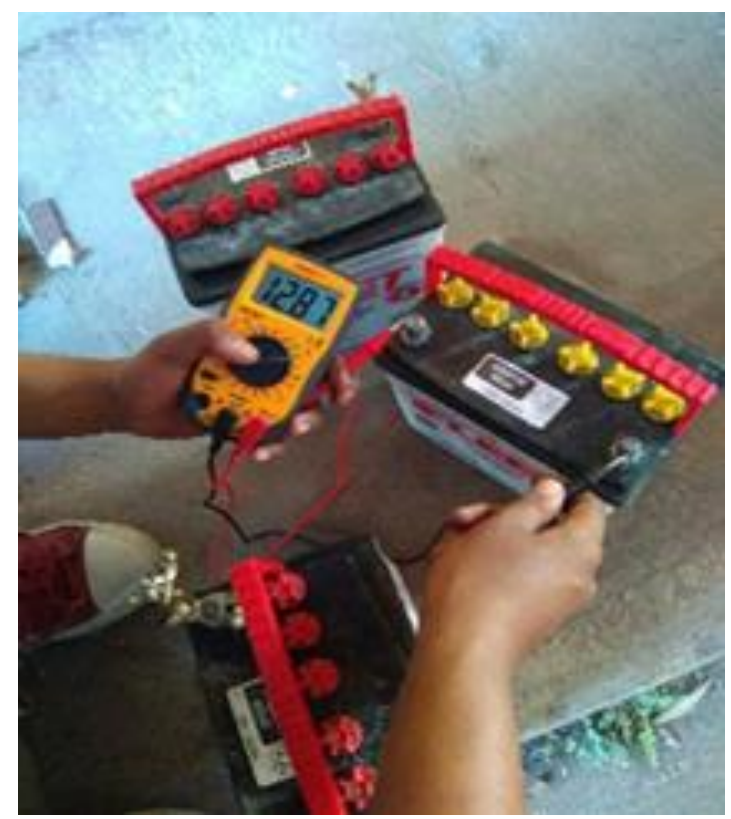

Gambar 8. Pemeriksaan Baterai

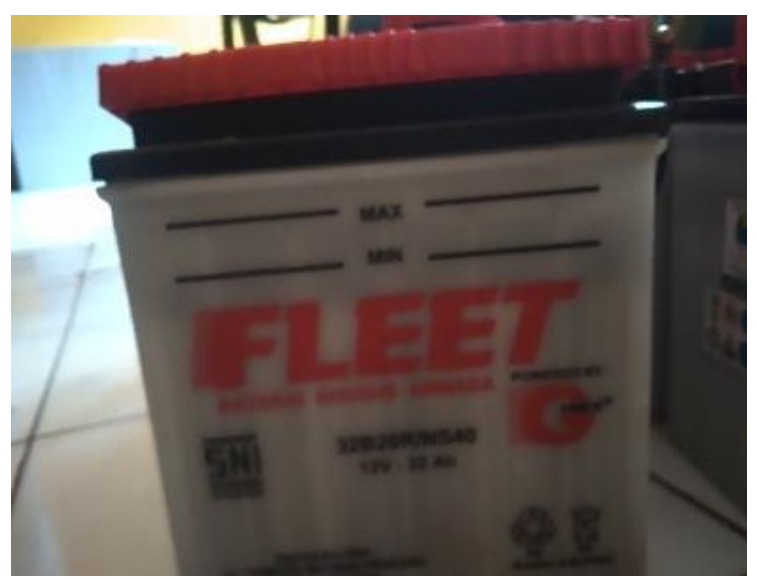

Gambar 9. Pemeriksaan Air Aki 
3. Menjaga Kebersihan Baterai

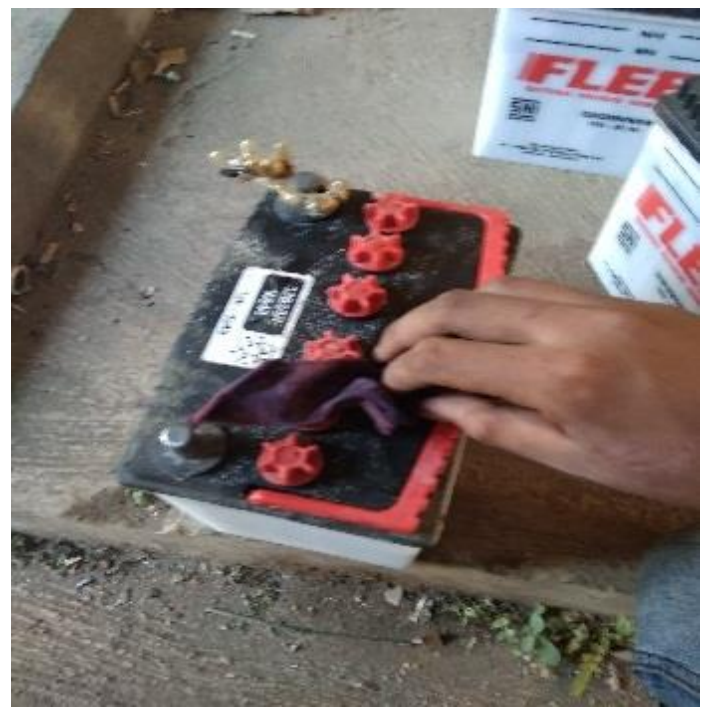

Gambar 10. Pembersihan Baterai

Hasil penelitian Zoni [11] baterai merupakan komponen yang harus mendapat perawatan, hal itu dikarenakan apabila terjadi penurunan tegangan pada kendaraan akan mempengaruhi performa mesin saat digunakan.

\section{Kesimpulan}

Hasil penelitian menunjukan bahwa pemeliharaan dilakukan secara bulanan dimana kegiatan yang dilakukan merupakan inspeksi sesuai jadwal pemeliharaan yang sudah direncanakan. Pemeliharaan mesin mobil sula dimaksudkan untuk menjaga kondisi mesin mobil tetap pada performa terbaik.

\section{Ucapan terima kasih}

Ucapan terima kasih kepada Kampus Politeknik Negeri Subang yang telah mendukung proses penelitian ini berjalan dengan lancar.

\section{Daftar Pustaka}

[1] Nyaga, M.J., Developing And Building A Prototype Rear Wheel Drive Electric Car. 2009 May.

[2] Guizani, A., Hammadi, M., Choley, J., Soriano, T., Mechanics I ndustry Electric vehicle design , modelling and optimization. 2016. March.

[3] Quandt, C.O., Innovation. Manufacturing the electric vehicle : a window of technological opportunity for Southern California, 1995 February.

[4] Corder., A., Teknik Manajemen Pemeliharaan. Jakarta, Erlangga; 1992

[5] Zemmouri, M., Activities Analyzing the Value of Vehicle Maintenance Activities. 2016.

[6] Rusuma, J., Developing a car maintenance service concept for business customers - a case study of Veho Autotalot Oy. Leppävaara: Laurea University of Applied Sciences, 2012.

[7] Efendi, A., Nugroho, Y.S., (2019). "Has the Electrical Laboratory of Subang State Polytechnic Applied,” vol. 2, no. 2, pp. 47-52. 
[8] Efendi, A., Komarudin, D. (2019). Evaluation of the Application of Occupational Safety and Health (OSH) at the Subang State Polytechnic Laboratory. Automotive Experiences, 2(1), 9-14.

[9] I. H. B. M. AMIN. Design And Analyze The Chassis Of An Electric Vehicle For Use In Campus Condition. Melaka: Universiti Teknikal Malaysia Melaka, 2018.

[10] Maccioni, F., Maintenance program for Electric Vehicles power train by Reliability Centred Maintenance, 2012.

[11] Zoni, M., Dc drive testing for prototype electric vehicles 1, 2017 vol. 12, no. 18, pp. 5339-5342.. 